\title{
Belongings Considered Harmful
}

Contributor: Eli Blevis

$\rightarrow$ Genre: Humor, unintended meanings
A sign - illustrated with smartphone and purse icons - advises "Beware of your belongings," which has the sense that your belongings might hurt you.
This is not quite the same as "Be aware of your belongings," which has the sense that someone may try to steal your belongings, the likely intended meaning.

DOI: $10.1145 / 2594441$ @ 2014 ACM 1072-5520/14/05 \$15.00

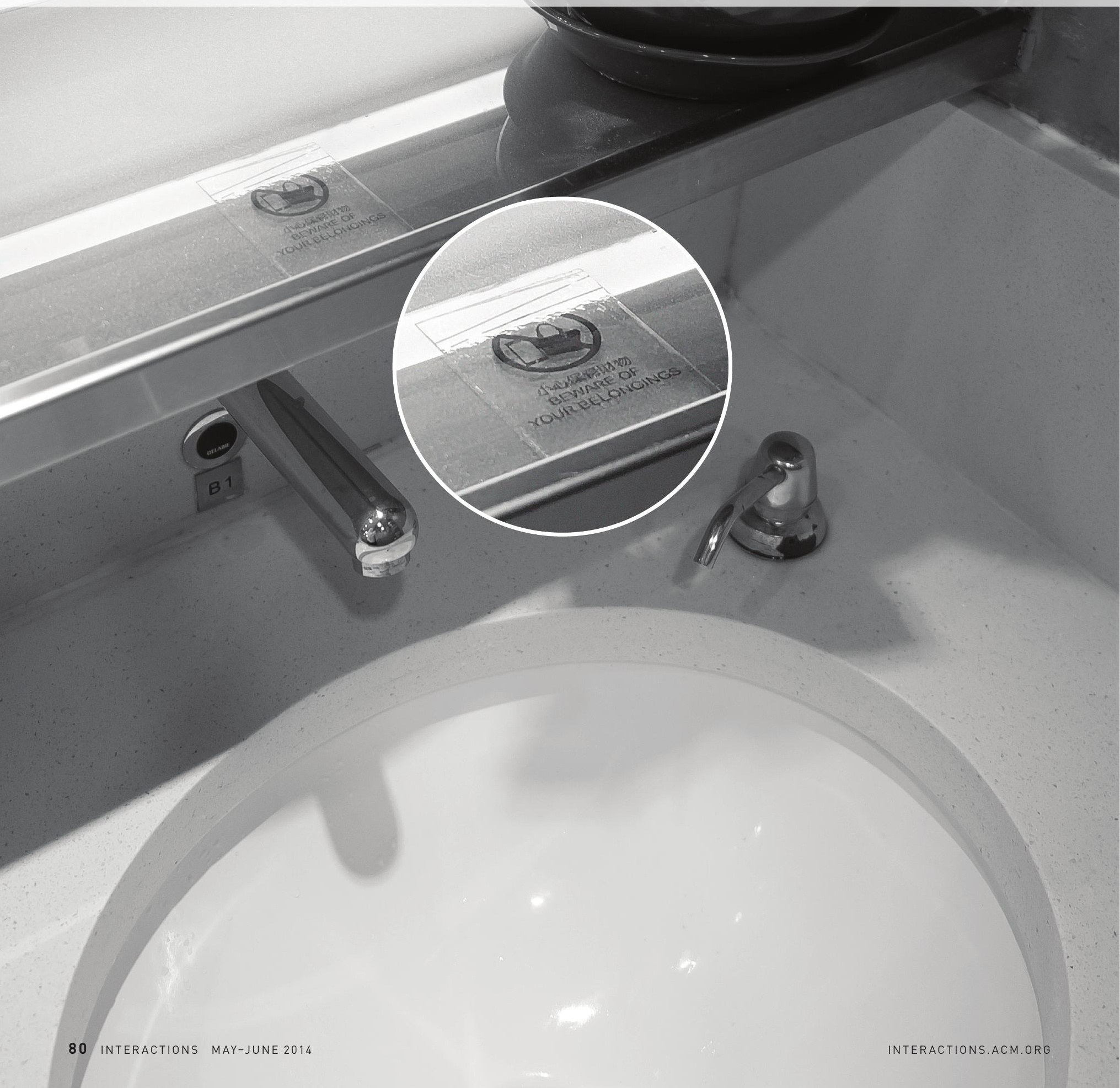

